\title{
Predictive Factors for Chronic Subdural Hematoma Recurrence
}

\author{
MOHAMMED F.A. ALI, M.D.*; HIDER AL-SHAMI, M.R.C.S., E.F.N.S.** and \\ HUSSEIN SOFFAR, M.D.* \\ The Department of Neurosurgery, Faculty of Medicine, Cairo University* and Bank Al-Ahly Hospital**
}

\begin{abstract}
Background: Recurrence of chronic subdural hematoma is a major impact on the clinical course during management. Literatures define several factors during their study.
\end{abstract}

Aim of Study: We aimed to investigate the predictive factors that may be responsible for CSDH recurrence in patients who underwent surgical evacuation at our center.

Patients and Methods: This was a retrospective analysis of medical records for patients who underwent surgical evacuation of CSDH at Kasr Al-Ainy University Hospital from July 2018 to August 2020. The diagnosis of CSDH was established by Computed Tomography (CT). The ethical approval was gained prior to data retrieval. The main inclusion criteria is the presence of CSDH on CT scan with neurological sequelae. It has been found that 54 medical records. Eleven cases were excluded from the study sample due to missing data. Finally, 43 patients' file were reviewed for analysis. Routine imaging of post-operative evacuation is achieved in the $1^{\text {st }}$ day, $1^{\text {st }}$ and $3^{\text {rd }}$ months.

Results: The mean and standard deviation of age was $64.71 \pm 12.65$ years, age range $45-88$ years. The male patients constituted $76.7 \%$ the interval between head trauma (found in $39.5 \%$ ) and surgery was up to 60 days. Multivariate analysis identified mixed density as the sole predictive value for recurrence $(\mathrm{OR}=16.8,95 \% \mathrm{CI}=13.4-20.2, p$-value $=0.021)$.

Conclusion: Recurrence of an evacuated chronic subdural hematoma is not uncommon phenomena. Presence of acute blood on top of chronic fluid (mixed density) is regarded as a risk factor for recurrence in the first month post-operatively.

Key Words: CSDH - Recurrence - Subdural hematoma.

\section{Introduction}

THE definition of Chronic Subdural Hematoma $(\mathrm{CSDH})$ is an abnormal collection of liquefied blood in subdural space that may lead to neurologically consequences [1,2]. The incidence is ranging from 1.72-20.6/100,000 per year [3-5]. The incidence in elderly age is more evident. The surgical

Correspondence to: Dr. Mohammed F.A. Ali, The Department of Neurosurgery, Faculty of Medicine, Cairo University treatment is the corner stone of CSDH with mass effect [6]. There are multiple options to evacuate the hematoma [7]. The main problem that facing neurosurgeons when dealing with CSDH is recurrence [5,8-11]. The recurrence rate is ranging from $5 \%$ to $30 \%[\mathbf{7 , 1 2 , 1 3 ]}$. Prediction of recurrence was extensively investigated previously in many literature $[3-5,7,8,10,14]$. In our study, we aimed to investigate the predictive factors that may be responsible for CSDH recurrence in patients who underwent surgical evacuation at our center.

\section{Material and Methods}

\section{Study design and recruitment:}

This was a retrospective analysis of medical records for patients who underwent surgical evacuation of CSDH at Kasr Al-Ainy University Hospital from July 2018 to August 2020. The diagnosis of CSDH was established by Computed Tomography $(\mathrm{CT})$. The ethical approval was gained prior to medical records recruitment. The main inclusion criteria is the presence of CSDH on CT scan with neurological sequelae that requires evacuation.

\section{Study parameters and predictive factors:}

The following parameters were collected; age, gender, symptomatology, duration, laterality, comorbidities (hypertension, DM or medications for coagulopathy), Markwalder's grading scale (Table $1)$, midline shifting ( $\mathrm{mm})$, cisternal compression, thickness of subdural hematoma $(\mathrm{mm})$ and finally the density of hematoma according to Hounsfiled Unit (HU) on Ct scan (Table 2).

Table (1): Markwalder grading scale.

Grade 0 - Neurologically intact

Grade 1 - Alert and oriented

Grade $2 \cdot$ Drowsy and disoriented

Grade 3 - Stuporous or focal signs such as hemiplegia

Grade 4 - Comatose with no motor response, decerebrate or decorticate posturing 
Table (2): Density of CSDH on CT scan.

\begin{tabular}{l}
\hline Low density $\quad<25 \mathrm{HU}^{*}$ \\
Isodensity $\quad 25-35 \mathrm{HU}$ \\
Hyper density $>35 \mathrm{HU}$ \\
Mixed density Mixed signals on CT scan
\end{tabular}

*HU: Hounsfiled Unit.

Study selection:

From July 2018 to August 2020, it has been found that 54 medical records with diagnosis of CSDH. Eleven cases were excluded from the study sample due to missing data. At the end, 43 patients' file were reviewed for appropriate statistical analysis.

\section{Follow-up:}

Routine imaging of post-operative evacuation is achieved in the ${ }^{1 \mathrm{st}}$ day, ${ }^{1 \mathrm{st}}$ and ${ }^{3 \mathrm{rd}}$ months. Emergent imaging is a must in case of the presence of symptoms suggestive of increased intracranial tension or development of focal deficit.

\section{Definition of recurrence:}

The definition of recurrence is increased volume of ipsilateral subdural hematoma on CT scan with signs of mass effect (increased intracranial tension or presence of neurological deficit).

\section{Statistical analysis:}

A univariate analysis was done with Pearson $\chi^{2}$ test or Fisher test. A Mann-Whitney U-test was utilized for noncategorical variables. Multivariate regression analysis was done for prediction of independent factors responsible for recurrence. A $p$-value below 0.05 was regarded as significant. The relationship between probable predictive factor and recurrence was expressed in Odds Ratio (OR) and $95 \%$ Confidence Interval (CI).

\section{Results}

Table (3): Factors related to recurrence of CSDH: Univariate and multivariate regression analysis.

\begin{tabular}{|c|c|c|c|c|c|}
\hline \multirow[t]{2}{*}{ Factor } & \multicolumn{2}{|c|}{$\begin{array}{l}\text { Number of patients } \\
(\%)\end{array}$} & \multirow{2}{*}{$\begin{array}{l}p \text {-value } \\
\text { univariate } \\
\text { regression } \\
\text { analysis }\end{array}$} & \multirow{2}{*}{$\begin{array}{c}p \text {-value } \\
\text { multivariate } \\
\text { regression } \\
\text { analysis }\end{array}$} & \multirow[t]{2}{*}{ OR, $95 \% \mathrm{CI}$} \\
\hline & No recurrence & Recurrence & & & \\
\hline Total & 36 & 7 & & & \\
\hline Sex (male) & $28(77 \%)$ & $5(71.4 \%)$ & & & \\
\hline Age (years) & $64.18 \pm 14.2$ & $65.25 \pm 11.1$ & 0.88 & 0.3 & $0.97(0.87-1.07)$ \\
\hline Bilateral hematoma & $10(27.7 \%)$ & $2(28.5 \%)$ & 0.27 & 0.9 & $0.81(0.79-0.83)$ \\
\hline Hypertension & $8 \quad(22.2 \%)$ & $2(28.5 \%)$ & 1.0 & 0.48 & $2.54(1.83-3.25)$ \\
\hline Diabetes mellitus & $10(27.7 \%)$ & $3(42.8 \%)$ & 1.0 & 0.99 & $4.22(3.71-4.73)$ \\
\hline Antiplatelet therapy & $9(25 \%)$ & $2(28.5 \%)$ & 0.11 & 0.65 & $0.66(0.15-1.17)$ \\
\hline Anticoagulant therapy & $9(25 \%)$ & $0(0 \%)$ & 1.0 & 0.99 & $0.56(0.3-0.82)$ \\
\hline \multicolumn{6}{|l|}{ Markwalder's grading scale: } \\
\hline 1 & $14(38.8 \%)$ & $5(71.4 \%)$ & & & \\
\hline 2 & $11(30.5 \%)$ & $2(28.5 \%)$ & & & \\
\hline 3 & $9(25 \%)$ & $0(0 \%)$ & & & \\
\hline 4 & $2(5.55 \%)$ & $0(0 \%)$ & & & \\
\hline Midline shift (mm) & $4.52 \pm 3.2$ & $6.97 \pm 3.9$ & 0.07 & 0.448 & $1.09(0.81-1.4)$ \\
\hline Cisterna ambience compression & $24(66 \%)$ & $7(100 \%)$ & $0.001 *$ & 0.88 & NA \\
\hline \multicolumn{6}{|l|}{ Density: } \\
\hline Isodensity & $21(58.3 \%)$ & $1(14.2 \%)$ & 0.112 & NA & NA \\
\hline Low density & $7(19.4 \%)$ & $0(0 \%)$ & 1.00 & NA & NA \\
\hline High density & $4(11.15)$ & $0(0 \%)$ & 1.00 & NA & NA \\
\hline Mixed density & $4(11.15 \%)$ & $6(85.7 \%)$ & $0.01 *$ & 0.021 & $16.8(13.4-20.2)$ \\
\hline Thickness of hematoma & $17.6 \pm 6.1$ & $22.4 \pm 8.18$ & 0.11 & 0.07 & $1.2(0.4-2)$ \\
\hline Organized hematoma & $1(2.77 \%)$ & $0(0 \%)$ & 1.0 & 0.99 & NA \\
\hline Thickness of post-operative pneumocephalus (mm) & $7.12 \pm 2.4$ & $7.14 \pm 1.1$ & 0.98 & 0.55 & $1.02(0.72-1.32)$ \\
\hline Thickness of post-operative liquid (mm) & $4.98 \pm 4.2$ & $5.12 \pm 3.3$ & 0.43 & 0.31 & $0.81(0.6-1.02)$ \\
\hline
\end{tabular}

The total number of patients' medical record were 43 . Only 7 cases $(16.27 \%)$ of patients had had recurrence that requires evacuation. Table (3) illustrate the demographic, clinical and radiological criteria of studied participants. The mean and standard deviation of age was $64.71 \pm 12.65$ years, age range $45-88$ years. The male patients constituted $76.7 \%$ the interval between head trauma (found in $39.5 \%$ ) and surgery was up to 60 days. Eleven patients received aspirin and 9 patients took war- 
farin prior to presentation. All patients required evacuation either by burr hole craniostomy or craniotomy. Burr hole craniostomy was done in 33 patients in non-recurrence group while all patients did this procedure in the recurrent one. Mortality rate was seen in five patients (11.6\%).
Two patients in recurrence group died between the $1^{\text {st }}$ and ${ }^{2 n d}$ week post-operatively due to myocardial infarction or respiratory failure. Univariate analysis showed mixed density and ambient cistern compression were associated with recurrence $(0.01$, $0.001)$ respectively.

Table (4): Recurrent CSDH cases in our retrospective analysis.

\begin{tabular}{|c|c|c|c|c|c|c|c|c|c|c|c|c|}
\hline No. & Age & Sex & $\begin{array}{l}\text { HTN/ } \\
\text { DM* }^{*}\end{array}$ & $\begin{array}{c}\text { Antiplatlet }+ \\
\text { Anticoag }\end{array}$ & $\begin{array}{l}\text { Mark- } \\
\text { walder's } \\
\text { G. S. }\end{array}$ & $\begin{array}{l}\text { Hemorrhage } \\
\text { side }\end{array}$ & $\begin{array}{l}\text { Midline } \\
\text { shift } \\
(\mathrm{mm})\end{array}$ & $\begin{array}{c}\text { Cisterna } \\
\text { Ambience } \\
\text { compression }\end{array}$ & Destiny & $\begin{array}{l}\text { Hematoma } \\
\text { Thickness }\end{array}$ & $\begin{array}{c}\text { Post- } \\
\text { operative } \\
\text { Gas (mm) }\end{array}$ & $\begin{array}{l}\text { Post- } \\
\text { operative } \\
\text { liquid }\end{array}$ \\
\hline 1 & 64 & M & No & No & 1 & Left & 11 & Yes & Mixed & 27 & 4 & 9 \\
\hline 2 & 63 & M & Yes & No & 1 & Right & 8 & Yes & Mixed & 14 & 9 & 5 \\
\hline 3 & 80 & $\mathrm{~F}$ & No & Yes & 2 & Right & 9 & Yes & $\begin{array}{l}\text { Iso- } \\
\text { density }\end{array}$ & 14 & 4 & 5 \\
\hline 4 & 74 & M & Yes & Yes & 1 & Left & 4 & Yes & Mixed & 36 & 9 & 10 \\
\hline 5 & 71 & $\mathrm{~F}$ & No & No & 1 & Left & 9 & Yes & Mixed & 14 & 4 & 4 \\
\hline 6 & 60 & M & Yes & No & 1 & Right & 14 & Yes & Mixed & 19 & 14 & 6 \\
\hline 7 & 55 & M & No & No & 2 & Right & 6 & Yes & Mixed & 24 & 4 & 8 \\
\hline
\end{tabular}

*HTN/DM: Hypertension or Diabetes Mellitus.

Multivariate analysis identified mixed density as the sole predictive value for recurrence $(\mathrm{OR}=$
$16.8,95 \% \mathrm{CI}=13.4-20.2, p$-value=0.021). Further description of recurrent cases in (Table 4).
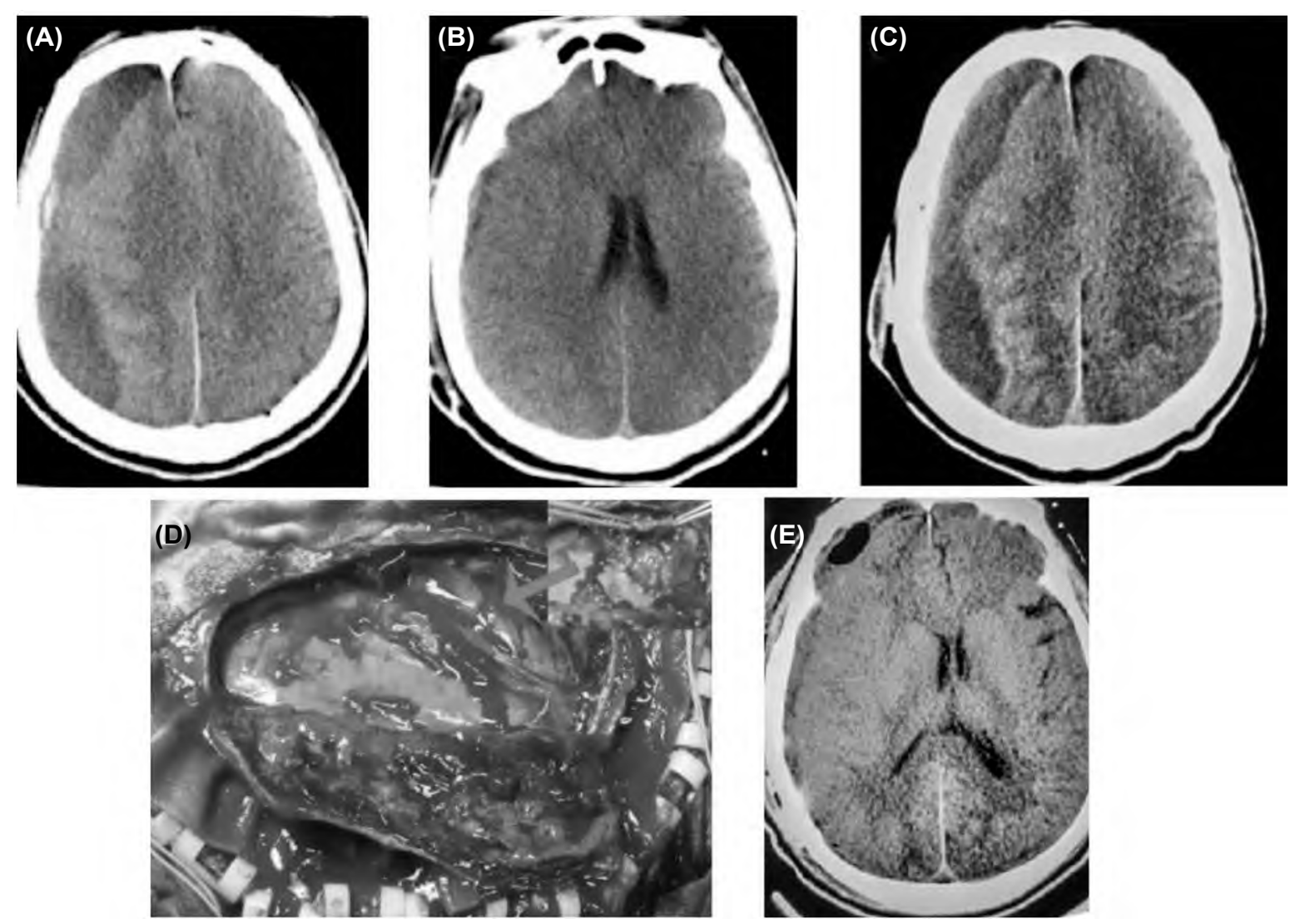

Fig. (1): A- Non contrast CT on first visit. B- CT scan after burrhole craniostomy. C- CT scan showed recollection. DIntraoperative image showed thick neomembrane. E- CT after craniotomy.

\section{Case presentation:}

A 65-year-old male patient with history of ischemic heart disease and antiplatelet therapy (aspirin) developed left sided weakness grade 4/5 with decreased consciousness over 7 days. CT scan showed right fronto-parietal chronic subdural hematoma with mixed density Fig. (1A). Reverse of antiplatelet therapy was achieved by giving platelet replacement prior to surgery. He underwent burr hole craniostomy. An immediate post-operative 
CT scan showed no fluid or gas in the subdural space Fig. (1B). He was discharged 4 days thereafter with improvement in his conscious level and hemiplegia. Eleven days post-operatively, he presented in the Emergency Department with deterioration in consciousness and re-emergence of left sided weakness. An immediate CT scan showed subdural collection extending from frontal to parietal region with midline shift $(>1 \mathrm{~cm})$ Fig. (1C). Craniotomy was done, we evacuate the collection and trimmed the thick inner neomembrane with hemostasis Fig. (1D). Patient was admitted to Intensive Care Unit for two days. His consciousness was improved dramatically as well as his weakness to be full motor power. Before discharge (on the $5^{\text {th }}$ day), CT scan was done which showed no fluid with minimal gas collection Fig. (1E).

\section{Discussion}

The risk factors for CSDH recurrence were mentioned previously in literatures $[\mathbf{1 , 2 , 1 1 , 1 2 , 1 5 ]}$. They are included advanced age, recent hemorrhage, intracranial hypotension, concomitant brain atrophy, bilateral hematoma, associated comorbidities like coagulopathy, post-operative subdural pneumocephalus and type of hematoma [8,10-12]. The mechanism of developing the subdural collection is being well understood. But what was a great question to neurosurgeons is the cause of recurrence apart from the technical faults. In this study as well as previous literature, the key players in successful CSDH evacuation are adequate drainage, return of neural tissue and prevention of recurrence [15-17]. In our logistic regression models, mixed density (i.e. acute on top of chronic hematoma) was found to be the sole factor responsible for recurrence. Certain literatures found similar finding $[10,18]$. All recurrent cases were operated at ${ }^{1 \text { st }}$ with burr hole craniostomy with mixed density hematoma. Recurrence was diagnosed at the ${ }^{\text {st }}$ fourteen days. Recurrence of subdural hematoma was not merely radiological but rather with clinical impact in the form of increased intracranial tension and positive neurological deficit. All recurrent cases were treated by craniotomy with strong evidence of thick inner neomembrane and organized hematoma. These two observations were found in all recurrent cases.

The thickened inner neomembrane is an important factor in CSDH recurrence in many published articles discussing this issue. Thin inner membrane can aid resolution of hematoma by facilitating neural tissue expansion and slow absorption of gas and liquid [10]. In contrast, the presence of thick one prevents neural tissue expansion. Previous literatures suggest removing the neomembrane to decrease chances of recurrence $[4,5,8,10]$. However, Sahyouni and colleagues [19] found no superior outcomes from removing the neomembrane in comparison with traditional burrhole craniostomy as regard outcome and complications.

The recurrence rate is ranging from 5\% to $33 \%$ in published articles. In our study, it was found to be $16.27 \%$. We used burr hole craniostomy with closed draining system as a method for evacuation of chronic subdural hematoma in our center. We noted that presence of liquid and gas are not preventive finding against recurrence. Certain reports of gas presence in the subdural hematoma is regarded as risk factor for recurrence [2,20]. Neither gas nor liquid in the subdural space post-operatively are predictive for recurrence in our study. Anticoagulant and antiplatelet medications are acting in reversible and temporary $[4,6,13,21,22]$. Neurosurgeons as well as anesthesiologists were used to reverse their actions pre-operatively by giving counteracting medications (e.g. Vitamin K) or replacement therapy (fresh frozen plasma or platelets). In our study, presence of anticoagulant or antiplatelet therapy were found to be of no predictive value.

The major limitation in our study is in its small sample size. Different operators were found during data retrieval which makes judjment of fixed technical skill is not established during analysis of data.

\section{Conclusion:}

Recurrence of an evacuated chronic subdural hematoma is not uncommon phenomena. Presence of acute blood on top of chronic fluid (mixed density) is regarded as a risk factor for recurrence in the first month post-operatively.

\section{Conflict of interest:}

Non to declare.

\section{References}

1- DOWLATI E., SARPONG K., TRIANO M., et al.: Outcomes of Surgical Evacuation of Chronic Subdural Hematoma in the Aged: Institutional Experience and Systematic Review. World Neurosurgery. Published online August. Doi:10.1016/j.wneu.2020.08.118, 2020.

2- TOMMISKA P., RAJ R., SCHWARTZ C., et al.: Finnish study of intraoperative irrigation versus drain alone after evacuation of chronic subdural haematoma (FINISH): A study protocol for a multicentre randomised controlled trial. BMJ Open, 10 (6): e038275. Doi: 10.1136/bmjopen2020-038275, 2020.

3- KANAZAWA T., TAKAHASHI S., MINAMI Y., JINZAKI M., TODA M. and YOSHIDA K.: Prediction of post- 
operative recurrence of chronic subdural hematoma using quantitative volumetric analysis in conjunction with computed tomography texture analysis. Journal of Clinical Neuroscience, 72: 270-6. Doi:10.1016/j.jocn.2019.11.019, 2020.

4- DOS SANTOS R.G., XANDER P.A.W., Da SILVA RODRIGUES L.H., FERREIRA Da COSTA G.H., VEIGA J.C.E. and de AGUIAR G.B.: Analysis of predisposing factors for chronic subdural hematoma recurrence. Revista da Associacao Medica Brasileira, 65 (6): 834-8. Doi: 10.1590/1806-9282.65.6.834, 2019.

5- ABDELFATAH M.R.: Recurrence rate of chronic subdural hematoma after evacuating it by two large burr holes, irrigation, and subgaleal low-pressure suction drainage. Asian Journal of Neurosurgery, 14 (3): 725, Doi: 10.4103/ ajns.ajns_321_17, 2019.

6- HUANG J., GAO C., DONG J., ZHANG J. and JIANG R.: Drug treatment of chronic subdural hematoma. Expert Opinion on Pharmacotherapy, 21 (4): 435-44, Doi: 10.1080/14656566.2020.1713095, 2020.

7- MARTINEZ-PEREZ R., TSIMPAS A., RAYO N., CEPEDA S. and LAGARES A.: Role of the patient comorbidity in the recurrence of chronic subdural hematomas. Neurosurgical Review. Published online March, Doi: 10.1007/ s10143-020-01274-7, 2020.

8- ZHUO J., XU Y., ZHANG J., ZHANG W., JI M. and WANG Y.: Prediction Models for Recurrence of Chronic Subdural Hematoma in Patients Underwent Twist-Drill Craniostomy Combined With Urokinase Instillation. The Journal of craniofacial surgery. Published online August, doi: 10.1097/SCS.0000000000006779, 2020.

9- GREUTER L., NADER H. and SOLEMAN J.: Type of drain in chronic subdural hematoma-a systematic review and meta-analysis. Frontiers in Neurology, 11: 312. Doi: 10.3389/fneur.2020.00312, 2020.

10- LIU L.X., CAO X.D., REN Y.M., ZHOU L.X. and YANG C.H.: Risk Factors for Recurrence of Chronic Subdural Hematoma: A Single Center Experience. World Neurosurgery, 132: e506-e513. Doi:10.1016/j.wneu.2019.08.089, 2019.

11- ZHANG P., LI Y., HUANG J., et al.: Chronic subdural haematoma in antithrombotic cohorts: Characteristics, surgical outcomes, and recurrence. British Journal of Neurosurgery. Published online April: 1-8. Doi: 10.1080/ 02688697.2020.1749987, 2020.

12- CHANG C.L., SIM J.L., DELGARDO M.W., RUAN D.T. and CONNOLLY E.S.: Predicting Chronic Subdural Hematoma Resolution and Time to Resolution Following Surgical Evacuation. Frontiers in Neurology, 11: 677. Doi: 10.3389/fneur.2020.00677, 2020.
13- BLAAUW J., JACOBS B., DEN HERTOG H.M., et al.: Neurosurgical and Perioperative Management of Chronic Subdural Hematoma. Frontiers in Neurology, 11: 550. Doi: 10.3389/fneur.2020.00550, 2020.

14- CHOI J., PYEN J., CHO S., KIM J., KOO Y. and WHANG K.: Influence of Antithrombotic Medication on the Risk of Chronic Subdural Hematoma Recurrence after BurrHole Surgery. Journal of Korean Neurosurgical Society. 63 (4): 513-8. Doi:10.3340/jkns.2019.0194, 2020.

15- WATANABE S., KATO N., SATO M., et al.: Treatment Outcomes of Burr-Hole Surgery for Chronic Subdural Hematoma in the Elderly Living Beyond Life Expectancy: A Study Comparing Cure, Recurrence, and Complications in Patients Aged $\geq 80$ Years versus $\leq 79$ Years. World Neurosurgery, 132: e812-e819. Doi: 10.1016/j.wneu. 2019.08.003, 2019.

16- RAUHALA M., HELÉN P., HUHTALA H., et al.: Chronic subdural hematoma-incidence, complications, and financial impact. Acta Neurochirurgica, 162 (9): 2033-43. Doi: 10.1007/s00701-020-04398-3, 2020.

17- GLANCZ L.J., POON M.T.C., HUTCHINSON P.J., KOLIAS A.G. and BRENNAN P.M.: Drains result in greater reduction of subdural width and midline shift in burr hole evacuation of chronic subdural haematoma. Acta Neurochirurgica, 162 (6): 1455-66. Doi: 10.1007/s00701-02004356-z, 2020.

18- SHIMIZU Y., PARK C. and TOKUDA K.: Gradation density hematoma is a predictor of chronic subdural hematoma recurrence associated with inflammation of the outer membrane. Clinical neurology and neurosurgery, 194: 105839. Doi:10.1016/j.clineuro.2020.105839, 2020.

19- SAHYOUNI R., MAHBOUBI H., TRAN P. and ROUFAIL J.S.: CJ. Membranectomy in chronic subdural hematoma: Meta-analysis. World Neurosurgery, 104: 418-29, 2017.

20- WU Q., LIU Q., CHEN D., et al.: Subdural drainage techniques for single burr-hole evacuation of chronic subdural hematoma: Two drains frontal-occipital position versus one drain frontal position. British Journal of Neurosurgery. Published online September: 1-5. Doi: 10.1080/02688697.2020.1812520, 2020.

21- SUERO MOLINA E., BORSCHEID L., FREISTÜHLER M., ZAWY ALSOFY S., STUMMER W. and SCHIPMANN S.: Risk-assessment in chronic subdural hematoma evaluated in 148 patients-A score for predicting recurrence. Clinical Neurology and Neurosurgery, 195: 106020. Doi: 10. 10 16/j.clineuro.2020.106020, 2020.

22- SHEN J., XIN W., LI Q., GAO Y. and ZHANG J.: A grading system for the prediction of unilateral chronic subdural hematoma recurrence after initial single burr hole evacuation. Risk Management and Healthcare Policy, 12: 179-88. Doi: 10.2147/RMHP.S222144, 2019. 


\section{العوامل التثبؤية لتكرار الورم الدموى الهومي تحت الآم الجاضية الهزئمار الومن التمون}

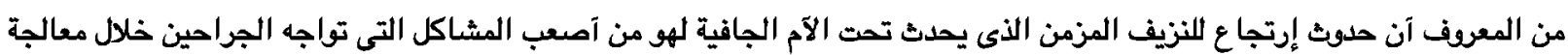

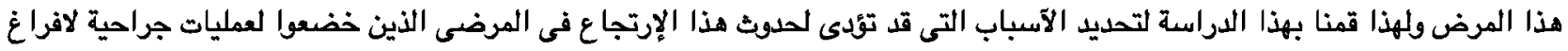
هذا النزيف.

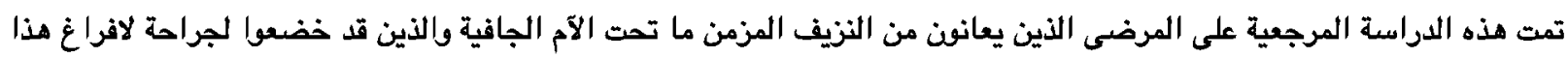

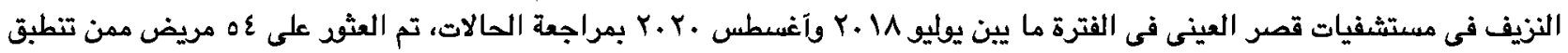

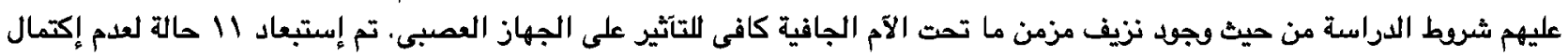

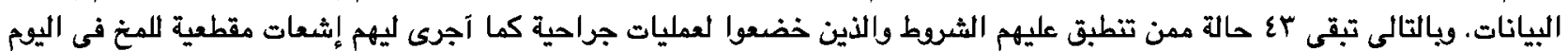

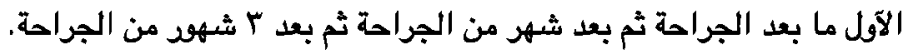

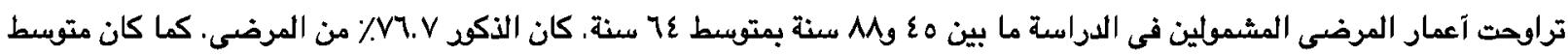

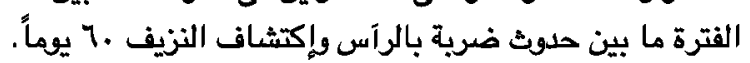

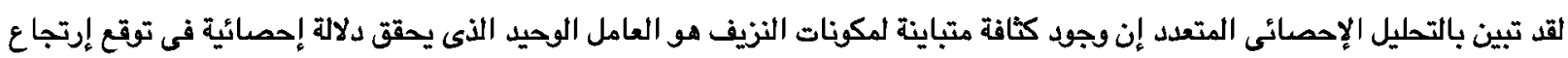
هذا النوع من النزيف وبخاصة في الشهر الآول فيما بعد إجراء الجناء الجراحة. 